\title{
Programming DNA replication origins and chromosome organization
}

\author{
Christelle Cayrou • Philippe Coulombe • \\ Marcel Méchali
}

Published online: 12 January 2010

(C) Springer Science+Business Media B.V. 2009

\begin{abstract}
During each cell cycle, thousands of DNA replication origins are activated in each cell of a metazoan organism. Although they appear site-specific, their usage and organization are rather plastic. Moreover, no strict sequence specificity has been observed in contrast to bacterial or Saccharomyces cerevisiae DNA replication origins. Epigenetic regulation linked to chromatin structure, chromosome organization, and transcription has been suggested to explain how DNA replication origins are selected and recognized by replication initiation factors. In this paper, we review these epigenetic features and discuss how, during the previous mitosis, chromosomal architecture might prepare DNA replication origins for a new cell cycle.
\end{abstract}

Keywords DNA replication origin - Chromatin . Nucleosome · DNA Loops · Transcription · Mitosis · Reprogramming

Abbreviations
$\begin{array}{ll}\text { Abfl } & \text { Autonomously replicating sequence } \\ & \text { binding factor } 1\end{array}$

Responsible Editor: Marie-Noëlle Prioleau and Dean Jackson.

C. Cayrou $\cdot$ P. Coulombe $\cdot$ M. Méchali $(\bowtie)$ Institute of Human Genetics, CNRS,

141 Rue de la Cardonille, 34980 Montpellier, France e-mail: mechali@igh.cnrs.fr
ACF

ARS

AT-rich

ATPases

BrdUTP

c-myc

CDC6

Cdt1

CHRAC

$\mathrm{CpG}$

DHFR

EBV

G-S period

Gcn5

$\mathrm{H} 3$ and $\mathrm{H} 4$

HAT

HBO1

HDAC

ING

Jade-1
ATP-dependent chromatin assembly and remodeling factor

Autonomously replicating sequence DNA sequences rich in adenine and thymine

Adenosine triphosphatase

Bromodeoxyuridine triphosphate

Cellular homolog of the oncogene

from myelocytomatosis virus

Cell division cycle 6, an ATPase

required for pre-RC formation

Cdc10-dependent transcript, a factor required for pre-RC formation Chromatin accessibility complex Cytosine guanine dinucleotide Dihydrofolate reductase Epstein-Barr virus Transition between G1 (gap 1) and S (DNA synthesis) phase of the cell cycle

General control of amino acid synthesis 5, a histone acetyltransferase Histone $\mathrm{H} 3$ and $\mathrm{H} 4$ Histone acetyltransferase Histone acetyltransferase binding to ORC 1

Histone deacetylase Inhibitor of growth Gene for apoptosis and differentiation in epithelia-1 


\begin{tabular}{|c|c|}
\hline LiS & Lithium 3,5-diiodosalicylate \\
\hline MARs & Matrix attachment regions \\
\hline MCM & Mini-chromosome maintenance \\
\hline ORC & Origin recognition complex \\
\hline OriP & Origin of plasmid replication \\
\hline poly-dA/dT & $\begin{array}{l}\text { DNA sequences containing tracks of } \\
\text { adenine and thymine }\end{array}$ \\
\hline e-RC & Pre-replication complex \\
\hline NA & Ribosomal RNA genes \\
\hline $\mathrm{d} 3$ & $\begin{array}{l}\text { Reduced potassium dependency } 3 \text {, a } \\
\text { histone deacetylase }\end{array}$ \\
\hline ARs & Scaffold attachment regions \\
\hline & $\begin{array}{l}\text { Silent information regulator } 2 \text {, a } \\
\text { histone deacetylase }\end{array}$ \\
\hline $\mathrm{JF} 2 \mathrm{H}$ & $\begin{array}{l}\text { Sucrose nonfermenting protein } 2 \\
\text { homolog, ATPase component of } \\
\text { chromatin remodeling complexes }\end{array}$ \\
\hline II/SNF & $\begin{array}{l}\text { SWItch/sucrose nonfermentable, a } \\
\text { yeast nucleosome remodeling } \\
\text { complex }\end{array}$ \\
\hline
\end{tabular}

\section{Introduction}

In any living organism, the entire genome should be faithfully duplicated during each cell cycle. DNA replication starts at DNA replication origins that must be activated only once during each $\mathrm{S}$ phase in order to maintain genome integrity. In Escherichia coli, a single DNA replication origin is sufficient to replicate the whole bacterial genome. This initiation site is at a fixed position in the genome and is defined by a strict genetic sequence (Jacob et al. 1963). In the unicellular eukaryote Saccharomyces cerevisiae, multiple DNA replication origins are also specified by a consensus sequence called autonomously replicating sequence (ARS). On the other hand, in Saccharomyces pombe, DNA replication origins do not have such consensus sequences and appear to rely on AT-rich islands (Dai et al. 2005; Heichinger et al. 2006; Segurado et al. 2003) and poly-dA/dT tracks (Okuno et al. 1999) for initiation. In multicellular organisms, no clear consensus sequence that characterizes replication origins has been identified to date. Moreover, origin recognition complexes (ORCs) that bind to DNA replication origins do not have a specificity for a particular sequence in vitro, suggesting that DNA replication origin position is not specified by DNA sequence alone (Vashee et al. 2003). In human or mouse cells, 30,000-50,000 DNA replication origins are activated at each cell cycle. In recent genome-wide analyses, some of these initiation sites have been mapped and shown to lie close to gene promoters that contained CpG islands (Cadoret et al. 2008; Sequeira-Mendes et al. 2009; our unpublished results). The absence of strict consensus sequences to define metazoan DNA replication origins led to question whether epigenetic mechanisms linked to chromatin structure and transcription might be the main determinants of replication origin localization in higher eukaryotes (Mechali 2001) for a review). In this paper, we review how genome organization could influence DNA replication origin localization and the plasticity of this localization during cell differentiation and reprogramming.

\section{Influence of chromatin structure on origin localization and activation}

In the nucleus, DNA is not naked but packaged with highly conserved histone proteins to form the basal element of chromatin structure: the nucleosome (Khorasanizadeh 2004). Accessibility to DNA sequence information could be therefore hindered by chromatin. However, chromatin features also serve as recognition marks for replication factors. Histone association with DNA is subjected to considerable regulation that can change the accessibility to a specific DNA sequence. Two major mechanisms are essential for modulating nucleosome organization and regulating access to the underlying DNA during the formation of the prereplication complex (pre-RC): nucleosome remodeling and modification of the histone tails.

\section{Nucleosome remodeling}

In order to allow recognition of DNA replication origins and formation of the replication complex, it is believed that DNA replication origins should be either nucleosome-free or contain nucleosomes that can be easily displaced. Indeed, DNA replication origins are usually enriched in open chromatin structures (Audit et al. 2009; Field et al. 2008; Zhou et al. 2005). Moreover, the formation of the replication complex requires several proteins in addition to ORC (reviewed in this issue), and thus, it is unlikely that it could accommodate the presence of fixed nucleosomes. 
Pioneer experiments in $S$. cerevisiae showed that the positioning of a nucleosome at a DNA replication origin inhibits initiation of replication at that origin (Simpson 1990). Similarly, Sir2 histone deacetylase inhibits DNA replication origin activity by favoring an unsuitable positioning of nucleosomes at DNA replication origins in S. cerevisiae (Crampton et al. 2008). The ORC complex may facilitate the formation of the pre-RC by influencing the positioning of nucleosomes (Lipford and Bell 2001).

Two major categories of nucleosome modifications have been implicated in the different processes of DNA replication. The first one, remodeling, concerns the movement and re-localization of nucleosomes relative to DNA sequences. Remodeling is carried out by members of a large family of ATPases which constitute the catalytic subunit of multi-protein complexes (Morettini et al. 2008). These complexes are involved in nucleosomal sliding (changes in nucleosome position relative to the DNA sequence) and nucleosome displacement (removal of histone octamers from DNA; Rippe et al. 2007). The second one concerns complexes that direct post-transcriptional histone modifications (Kouzarides 2007). This mechanism controls chromatin access by adding or removing covalent modifications (such as acetylation, methylation, phosphorylation, ribosylation, or ubiquitylation) on the N-terminal tails of histones. Nucleosomal positioning at DNA replication origins is regulated by different remodeling complexes. Knockdown of the catalytic subunit $S N F 2 H$, a member of the human chromatin accessibility complex (CHRAC) and ATPdependent chromatin assembly and remodeling factor (ACF) complexes, decreases MCM3 binding to the Epstein-Barr virus DNA replication origin OriP and reduces origin firing (Zhou et al. 2005). Also, ySWI/ SNF increases replication efficiency by stabilizing minichromosomes and increasing DNA replication origin initiation in $S$. cerevisiae (Flanagan and Peterson 1999). ISWI and ACF1 have especially important roles for replication of late-replicating regions (Collins et al. 2002; Vincent et al. 2008).

Transcription and DNA replication origins

Chromatin remodeling at DNA replication origins might also be a consequence of transcriptional regulation of the genes associated with these origins. The presence of transcription factor-binding motifs is an important determinant of nucleosome depletion (Bernstein et al. 2004; Yuan et al. 2005). In S. cerevisiae, DNA replication origins contain binding sites for the transcription factor Abf1 that could help origin activation (Diffley and Stillman 1989). In $S$. pombe as well as in higher eukaryotes, DNA replication origins are often located at promoters (Cadoret et al. 2008; Dai et al. 2005; Sequeira-Mendes et al. 2009; our unpublished data). Transcription factors can affect DNA replication origin localization or activation in different systems (Cheng et al. 1992; Danis et al. 2004; Ghosh et al. 2004; Maric et al. 2003; Minami et al. 2006; Sasaki et al. 2006). This could be achieved by recruiting chromatin remodeling and histone-modifying complexes (Fig. 1) or by a direct interaction with pre-RC components (Kohzaki and Murakami 2005 for review).

Generally, transcriptionally active promoters are hyper-acetylated on histones $\mathrm{H} 3$ and $\mathrm{H} 4$ (Berger 2007) and as a result maintain an open chromatin structure, which is a favorable substrate for initiation of DNA replication. Gcn5, a histone acetyl transferase (HAT) that is associated with transcriptional activity (Rodriguez-Navarro 2009), increases DNA replication when it is tethered to a yeast DNA replication origin (Vogelauer et al. 2002).

\section{Chromatin modifications at DNA replication origins}

Temperature-sensitive mutations in the pre-replication complex components ORC, CDC6, and MCM can be suppressed by inactivation of SIR2, a histone deacetylase (HDAC; Pappas et al. 2004). The HDAC Sir2p is also a negative regulator of chromosomal DNA replication (Pappas et al. 2004) and controls the frequency of DNA replication origin firing within rDNA (Pasero et al. 2002). Some yeast ARS elements contain specific sequences recognized by Sir2p that inhibit DNA replication origin activity, most likely by affecting the local chromatin structure (Crampton et al. 2008). Consistent with these observations, targeting the Rpd3 HDAC to a Drosophila DNA replication origin decreased its activity. Conversely, Chameau, the HAT responsible for DNA replication origin activation, increased $\mathrm{H} 4$ acetylation at ORC binding sites, leading to stronger origin activity (Aggarwal and Calvi 2004). Interestingly, the mammalian homologue of Chameau 

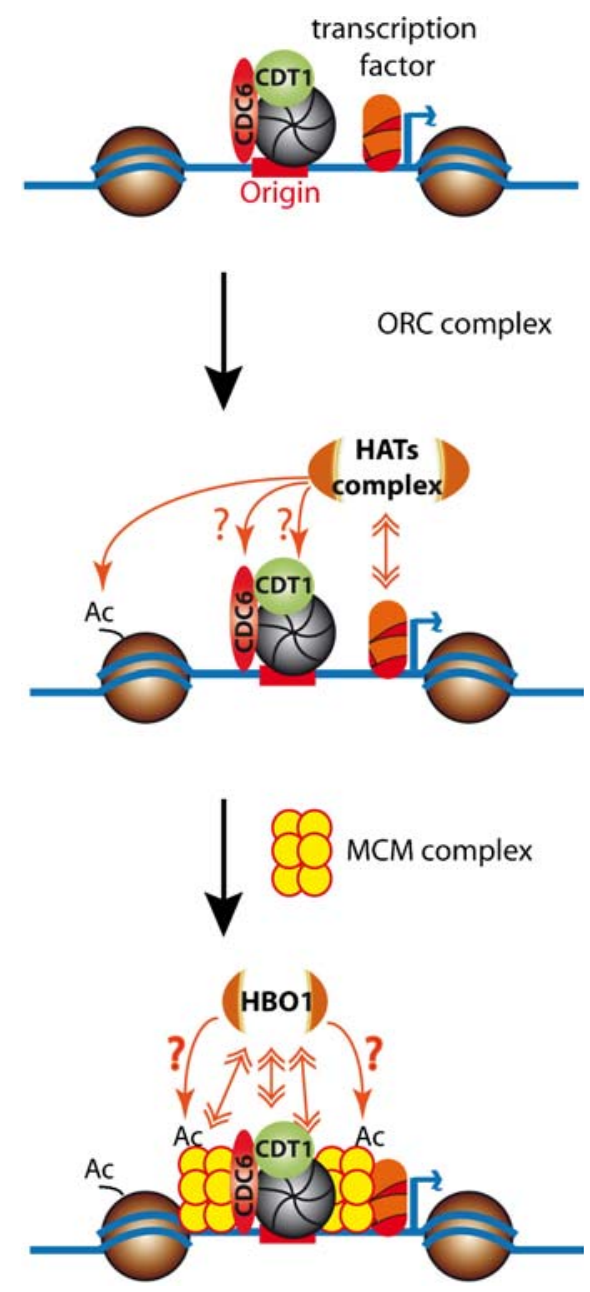

Fig. 1 Interplay between transcription factors, acetylation and DNA replication origin recognition. The ORC complex binds to an origin of DNA replication in the vicinity of a transcription factor. By recruiting HAT complexes, transcription factors can induce pre-RC activation through modification of ORC, CDT1, or CDC6. HAT complexes also acetylate surrounding nucleosomes and provide an environment favorable to recruitment of MCMs complexes onto chromatin. HBO1 might further acetylate one or more subunits of the MCM complex

is histone acetyltransferase binding to ORC 1 (HBO1), the catalytic subunit of a multi-protein complex that includes two tumor suppressor proteins, ING4 and 5, and two regulatory isoforms of the JADE-1 protein (Doyon et al. 2006); HBO1 derives its name from the ability to interact with ORC1 and MCM2 (Burke et al. 2001; Iizuka and Stillman 1999).

HBO1 is found in two different complexes (Fig. 2), one with ING4 (for transcription activity) and another one with ING5 (for DNA replication activity), which also contains three subunits of the MCM helicase that binds to replication origins. This complex is responsible for the major acetylation of histone $\mathrm{H} 4$ on lysine 5,8 , and 12. Knockdown of HBOI or ING5 causes a decrease in DNA synthesis and affects progression through $\mathrm{S}$ phase. In both Xenopus laevis and in
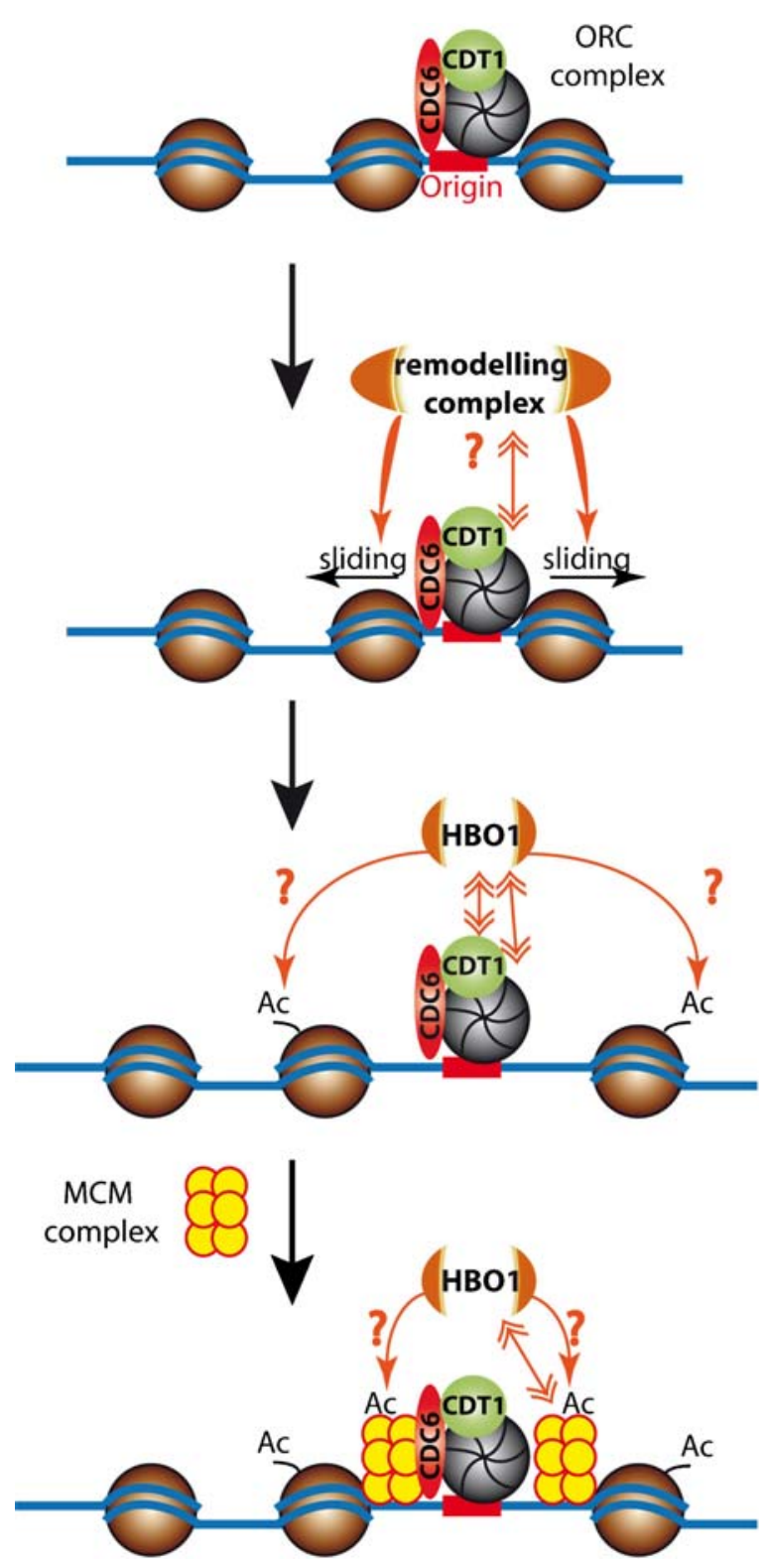

Fig. 2 Chromatin remodeling and origin recognition. Chromatin remodeling complexes recruited at DNA replication origins through interactions with pre-RC proteins might permit acetylation of surrounding nucleosomes by HAT complexes and a change in nucleosome position relative to the DNA sequence. This might facilitate MCM recruitment onto DNA replication origins. HBO1 could also bind to MCM2 and acetylate one or more subunits of the MCM complex 
human cells, $H B O 1$ depletion inhibits the recruitment of MCM complex to chromatin (Iizuka et al. 2006; $\mathrm{Wu}$ and Liu 2008). Recent findings in mammalian cells link HBO1 to Cdt1 (a crucial pre-RC component) as a co-activator of replication licensing (Miotto and Struhl 2008). Moreover, binding of HBO1 to the Kaposi's sarcoma-associated herpes virus terminal repeats (the origin of viral DNA replication) contributes to replication of the viral genome (Stedman et al. 2004). Together, these findings suggest that HBO1, via its ability to acetylate $\mathrm{H} 4$ on lysine 5,8 , and 12 , is required for pre-RC formation at DNA replication origins, but whether acetylation of histones is a general feature of DNA replication origins remains to be demonstrated (Cadoret et al. 2008; Dazy et al. 2006; Gregoire et al. 2006).

\section{Higher levels of chromatin organization}

Loops, matrix, and DNA replication origins

The coordinated activation of DNA replication origins takes place in specific nuclear structures called DNA replication foci (Fig. 3). When short BrdUTP or biotin-dUTP pulses are performed during $\mathrm{S}$ phase, several hundred foci can be revealed by indirect immunodetection of the labeled precursor analogues (Jackson 1995; Jackson and Pombo 1998; Ma et al. 1998; Nakamura et al. 1986). Similar structures have been described in eukaryotes ranging from yeast to human cells. The DNA foci that are labeled by this approach appear as stable units of chromosome structure which can be visualized as discrete units in individual chromosome territories (Berezney et al. 2000). They are believed to be organized as clusters of chro- matin loops that can be detected when most of the chromatin proteins are removed by extracting nuclei with high salt or with lithium 3,5-diiodosalicylate. A residual nuclear structure consisting of loop domains anchored to a nuclear skeleton is then observed (reviewed in Gilbert and Gasser 2006). This residual network is often called the nuclear matrix or scaffold and has been found in both animal and plant nuclei. This architecture of loop domains has been suggested to play an important role in organizing chromosomes for replication (Vogelstein et al. 1980). Despite an abundant literature, this finding remains controversial, although a similar nucleoskeleton was also observed using physiological extraction conditions (Jackson and Cook 1986).

Genomic DNA contacts the nuclear matrix at specific sites called matrix attachment regions (MARs or SARs for scaffold attachment regions) that are relatively resistant to DNAse digestion of extracted nuclei. MARs are $0.5-$ to $3-\mathrm{kb}$ regions often found at the $5^{\prime}$ of genes (Glazko et al. 2003). The specific DNA/matrix contacts yield inter-MAR loops ranging from 20 to $200 \mathrm{~kb}$ (Jackson et al. 1990), which vary depending on the cell cycle and cell identity. Matrix attachment sites are also associated with binding sites for topoisomerase II (Razin et al. 1991), an enzyme which is essential for loop remodeling. Recently, the first genome-wide studies to localize MARs were performed in human cells (Linnemann et al. 2007; Linnemann et al. 2009). As expected, a significant proportion of MARs were found to be associated with expressed genes. DNA replication origins also follow the same trend (unpublished data). However, it is clear that strong bias was observed depending on the method used to purify matrices, indicating that their preparation is still a sensitive aspect of experimental design.
Fig. 3 DNA replication foci and clusters of replication origins. Replication foci were identified by biotin-dUTP pulse during DNA synthesis in Xenopus egg extract. A single nucleus is shown. Replication foci are thought to occur by association of several replicons that are synchronously activated in each focus

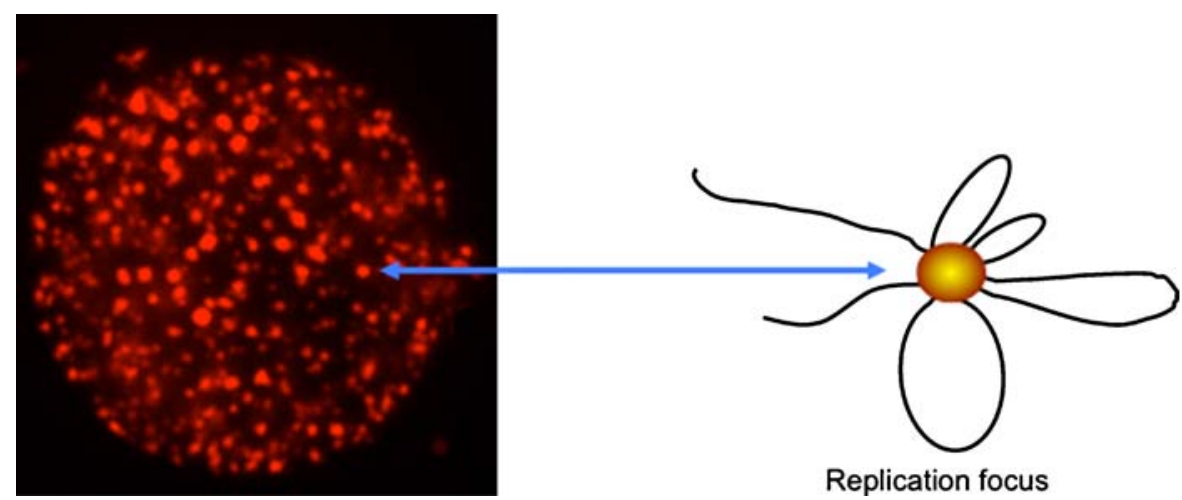


Numerous observations suggest a functional link between MARs and origins of DNA replication. First, many MARs are associated with origins of DNA replication. Indeed, MARs have been found at or very close to the chicken lysozyme DNA replication origin (Phi and Straetling 1988), the DHFR origins $\beta$ and $\beta^{\prime}$ (Dijkwel and Hamlin 1988), the lamin B2 origin (Lagarkova et al. 1998), and the c-myc origin (GirardReydet et al. 2004). Interestingly, origins/MARs association is a conserved feature (Girard-Reydet et al. 2004). Secondly, MAR-associated sequences are enriched in replication intermediates (Dijkwel et al. 1991). Lastly, the addition of MAR sequences to plasmids enhances their episomal replication (Papapetrou et al. 2006). MARs, together with DNA replication origin sequences, allow propagation of plasmid DNA without the use of selection agents (Jenke et al. 2004). In addition, MARs enhance stable transgene expression, possibly through their chromatin-organizing activity (Harraghy et al. 2008).

What is the link between MARs and DNA replication origins? By bringing specific DNA sequences to the matrix, MARs could facilitate the formation of replication initiation complexes. Also, MARs could link several DNA replication origins together at the nuclear matrix, resulting in clustered origins and thus facilitating their coordinated firing (Eivazova et al. 2009). MARs are also AT-rich sequences (Mirkovitch et al. 1984), and such AT richness could stimulate
DNA replication origin activation because of its unique DNA unwinding properties.

\section{Programming DNA replication origins and chromosome architecture}

Several recent studies have revived the links between DNA loops, replicons, and DNA replication origins. A compelling correlation between replicons and chromatin loops was initially reported by Buongiorno-Nardelli et al. (1982) who showed that the size of replicons was identical to the size of DNA loops in several animal and plant species, as well as during development in Xenopus. Pioneering experiments in Xenopus showed that a nucleus from a differentiated cell could be reprogrammed after transplantation into an enucleated egg (Gurdon 1962). However, the success of such cloning experiments was low (3 to 5\%) and still remains low (under 10\%) whatever animal species is used. It has been postulated that one of the main reasons for this low efficiency is that the genome from differentiated cells had to accommodate the rapid DNA replication cycles that are characteristic of early development.

When nuclei from differentiated cells are introduced in Xenopus egg extracts competent for S phase, they replicate rather slowly and with inter-origin spacing similar to that seen in somatic cells $(90 \mathrm{kbp})$. This
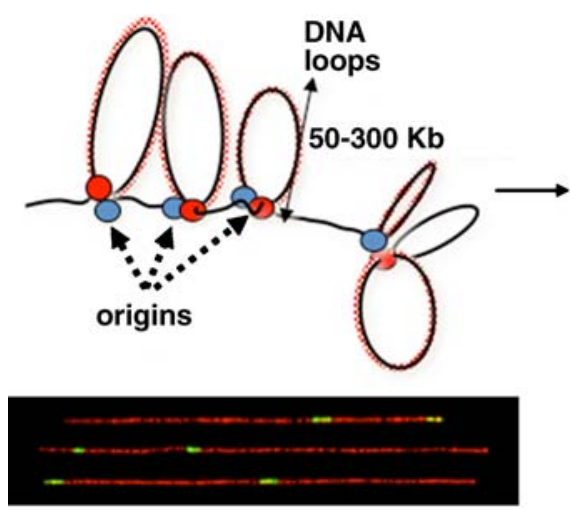

Differentiated

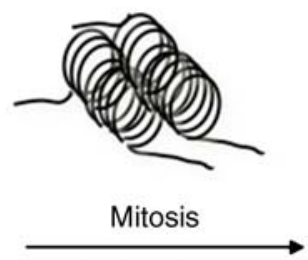

Topoll

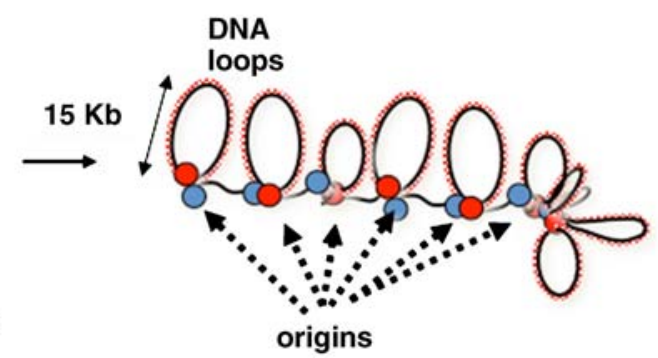

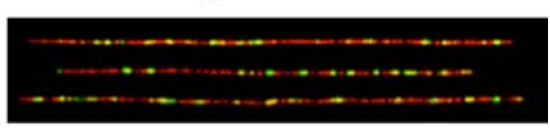

Reprogrammed
Fig. 4 Reprogramming of DNA replication origins during mitosis. Mitosis can reset DNA replication origins and adapt the replication of chromosomes to a new cell program. The organization of chromatin loops and the density of DNA replication origins of a differentiated nucleus can be fully remodeled by passing through mitosis in an egg extract. This process is topoisomerase II-dependent. DNA replication origins are thus set at short intervals $(10-15 \mathrm{kbp})$, as required for the rapid rounds of DNA replication that occur during early stages of Xenopus development 
contrasts with the much shorter inter-origin spacing characteristic of early Xenopus embryos ( $15 \mathrm{kbp})$ and also with the DNA replication origin spacing in sperm nuclei incubated with Xenopus egg extracts. However, when nuclei from differentiated, somatic cells were conditioned in mitotic egg extracts before transplantation, they gained the short inter-origin spacing typical of $\mathrm{S}$ phase induction. Strikingly, replicons were reprogrammed by passing through mitosis first. A similar observation was later made in mammalian cells, confirming this result (Courbet et al. 2008). Specifically, in these cells, a reduction in the concentration of replication precursor pools led to a decrease of fork speed and was associated with an increase in number of active replication origins. Interestingly, as previously observed in Xenopus, passing through mitosis was essential for fixing origin usage, and shorter replicons were seen in the following $\mathrm{S}$ phase even when the precursor pools were restored.

These observations imply that an event occurring at mitosis is important to allow the selection of DNA replication origins that can be used in the next cell cycle (Fig. 4). This step appears crucial for reprogramming nuclei during early development, and it was indeed shown that the transfer of mouse somatic nuclei in mitotic zygotes improves reprogramming in mouse as well (Egli et al. 2007). What is the mechanism responsible for this phenomenon? A similar analysis on the loop size in Xenopus led to the conclusion that exposure of differentiated nuclei to mitotic conditions in Xenopus egg extracts induces a global change in their chromosomal architecture. Specifically, when erythrocyte nuclei were exposed to such extracts, their average DNA loop size fell from 97 to $15 \mathrm{kpb}$. A similar correlation between replicon size and loop size was observed in mammalian cells (Courbet et al. 2008). In Xenopus, remodeling of both the loop size and of the DNA replication origin spacing is controlled by topoisomerase II (Lemaitre et al. 2005). This is in agreement with the observation that topoisomerase II is an enzyme associated with the nuclear matrix (Earnshaw and Heck 1985). Reprogramming of the distribution of DNA replication origins correlates with ORC recruitment to chromatin, which is also topoisomerase II-dependent (Lemaitre et al. 2005).

Together, these data from two different animal species indicate that mitosis is a crucial step for programming the chromosomal architecture that is used to define the regulation of DNA synthesis during the following S phase. Events that occur during G-S period of the cell cycle, where the distribution of potential origins is defined (Wu and Gilbert 1996), are thus also dependent on previous mitotic events. Although chromosomal loops and loop anchors are still poorly defined biochemically, these data suggest that chromosome architecture plays a predominant role in the regulation of DNA replication origin localization and activation. How ORC, the main origin recognition protein, recognizes this architecture is still unknown. Over recent years, several new members of the replication initiation complex have been identified. Unraveling how these complexes interact with eukaryotic chromatin might help to explain how DNA loops and chromatin domains are formed and if/how the structure of replication domains participates in gene expression and the control of cell identity.

Acknowledgments We would like to thank E. Andermarcher for critical reading of this manuscript. CC was supported by the FRM and PC was supported by the FRM and ARC. Our laboratory is supported by the European Research Council, by the ANR, the "Association pour la Recherche contre le Cancer" and the "Ligue Nationale contre le Cancer".

\section{References}

Aggarwal BD, Calvi BR (2004) Chromatin regulates origin activity in Drosophila follicle cells. Nature 430: 372-376

Audit B, Zaghloul L, Vaillant C, Chevereau G, d'AubentonCarafa Y, Thermes C, Arneodo A (2009) Open chromatin encoded in DNA sequence is the signature of 'master' replication origins in human cells. Nucleic Acids Res 37: 6064-6075

Berezney R, Dubey DD, Huberman JA (2000) Heterogeneity of eukaryotic replicons, replicon clusters, and replication foci. Chromosoma 108:471-484

Berger SL (2007) The complex language of chromatin regulation during transcription. Nature 447:407-412

Bernstein BE, Liu CL, Humphrey EL, Perlstein EO, Schreiber SL (2004) Global nucleosome occupancy in yeast. Genome Biol 5:R62

Buongiorno-Nardelli M, Micheli G, Carri MT, Marilley M (1982) A relationship between replicon size and supercoiled loop domains in the eukaryotic genome. Nature 298: $100-102$

Burke TW, Cook JG, Asano M, Nevins JR (2001) Replication factors MCM2 and ORC1 interact with the histone acetyltransferase HBO1. J Biol Chem 276:15397-15408

Cadoret JC, Meisch F, Hassan-Zadeh V, Luyten I, Guillet C, Duret L, Quesneville H, Prioleau MN (2008) Genomewide studies highlight indirect links between human replication origins and gene regulation. Proc Natl Acad Sci U S A 105:15837-15842 
Cheng LZ, Workman JL, Kingston RE, Kelly TJ (1992) Regulation of DNA replication in vitro by the transcriptional activation domain of GAL4-VP16. Proc Natl Acad Sci U S A 89:589-593

Collins N, Poot RA, Kukimoto I, Garcia-Jimenez C, Dellaire G, Varga-Weisz PD (2002) An ACF1-ISWI chromatinremodeling complex is required for DNA replication through heterochromatin. Nat Genet 32:627-632

Courbet S, Gay S, Arnoult N, Wronka G, Anglana M, Brison O, Debatisse M (2008) Replication fork movement sets chromatin loop size and origin choice in mammalian cells. Nature 455:557-560

Crampton A, Chang F, Pappas DL Jr, Frisch RL, Weinreich M (2008) An ARS element inhibits DNA replication through a SIR2-dependent mechanism. Mol Cell 30:156-166

Dai J, Chuang RY, Kelly TJ (2005) DNA replication origins in the Schizosaccharomyces pombe genome. Proc Natl Acad Sci U S A 102:337-342

Danis E, Brodolin K, Menut S, Maiorano D, Girard-Reydet C, Mechali M (2004) Specification of a DNA replication origin by a transcription complex. Nat Cell Biol 6:721-730

Dazy S, Gandrillon O, Hyrien O, Prioleau MN (2006) Broadening of DNA replication origin usage during metazoan cell differentiation. EMBO Rep 7:806-811

Diffley JF, Stillman B (1989) Similarity between the transcriptional silencer binding proteins ABF1 and RAP1. Science 246:1034-1038

Dijkwel PA, Hamlin JL (1988) Matrix attachment regions are positioned near replication initiation sites, genes and an interamplicon junction in the amplified dihydrofolate reductase domain of CHO cells. Mol Cell Biol 8:5398-5409

Dijkwel PA, Vaughn JP, Hamlin JL (1991) Mapping of replication initiation sites in mammalian genomes by two-dimensional gel analysis: stabilization and enrichment of replication intermediates by isolation on the nuclear matrix. Mol Cell Biol 11:3850-3859

Doyon Y, Cayrou C, Ullah M, Landry AJ, Cote V, Selleck W, Lane WS, Tan S, Yang XJ, Cote J (2006) ING tumor suppressor proteins are critical regulators of chromatin acetylation required for genome expression and perpetuation. Mol Cell 21:51-64

Earnshaw WC, Heck M (1985) Localization of topoisomerase II in mitotic chromosomes. J Cell Biol 100:1716-1722

Egli D, Rosains J, Birkhoff G, Eggan K (2007) Developmental reprogramming after chromosome transfer into mitotic mouse zygotes. Nature 447:679-685

Eivazova ER, Gavrilov A, Pirozhkova I, Petrov A, Iarovaia OV, Razin SV, Lipinski M, Vassetzky YS (2009) Interaction in vivo between the two matrix attachment regions flanking a single chromatin loop. J Mol Biol 386:929-937

Field Y, Kaplan N, Fondufe-Mittendorf Y, Moore IK, Sharon E, Lubling Y, Widom J, Segal E (2008) Distinct modes of regulation by chromatin encoded through nucleosome positioning signals. PLoS Comput Biol 4:e1000216

Flanagan JF, Peterson CL (1999) A role for the yeast SWI/SNF complex in DNA replication. Nucleic Acids Res 27:20222028

Ghosh M, Liu G, Randall G, Bevington J, Leffak M (2004) Transcription factor binding and induced transcription alter chromosomal c-myc replicator activity. Mol Cell Biol 24:10193-10207
Gilbert DM, Gasser SM (2006) DNA replication and nuclear architecture. In: DePamphilis ML (ed) DNA replication and human disease. Cold Spring Harbor Laboratory Press, New York, p 155

Girard-Reydet C, Gregoire D, Vassetzky Y, Mechali M (2004) DNA replication initiates at domains overlapping with nuclear matrix attachment regions in the xenopus and mouse c-myc promoter. Gene 332:129-138

Glazko GV, Koonin EV, Rogozin IB, Shabalina SA (2003) A significant fraction of conserved noncoding DNA in human and mouse consists of predicted matrix attachment regions. Trends Genet 19:119-124

Gregoire D, Brodolin K, Mechali M (2006) HoxB domain induction silences DNA replication origins in the locus and specifies a single origin at its boundary. EMBO Rep $7: 812-816$

Gurdon JB (1962) The developmental capacity of nuclei taken from intestinal epithelium cells of feeding tadpoles. J Embryol Exp Morphol 10:622-640

Harraghy N, Gaussin A, Mermod N (2008) Sustained transgene expression using MAR elements. Curr Gene Ther 8:353-366

Heichinger C, Penkett CJ, Bahler J, Nurse P (2006) Genomewide characterization of fission yeast DNA replication origins. Embo J 25:5171-5179

Iizuka M, Stillman B (1999) Histone acetyltransferase HBO1 interacts with the ORC1 subunit of the human initiator protein. Journal of Biological Chemistry 274:2302723034

Iizuka M, Matsui T, Takisawa H, Smith MM (2006) Regulation of replication licensing by acetyltransferase Hbo1. Mol Cell Biol 26:1098-1108

Jackson DA (1995) Nuclear organization: uniting replication foci, chromatin domains and chromosome structure. Bioessays 17:587-591

Jackson DA, Cook PR (1986) Replication occurs at a nucleoskeleton. Embo J 5:1403-1410

Jackson DA, Pombo A (1998) Replicon clusters are stable units of chromosome structure: evidence that nuclear organization contributes to the efficient activation and propagation of S phase in human cells. J Cell Biol 140:1285-1295

Jackson DA, Dickinson P, Cook PR (1990) The size of chromatin loops in HeLa cells. Embo J 9:567-571

Jacob F, Brenner J, Cuzin F (1963) On the regulation of DNA replication in bacteria. Cold Spring Harbor Symp Quant Biol 28:329-348

Jenke AC, Stehle IM, Herrmann F, Eisenberger T, Baiker A, Bode J, Fackelmayer FO, Lipps HJ (2004) Nuclear scaffold/matrix attached region modules linked to a transcription unit are sufficient for replication and maintenance of a mammalian episome. Proc Natl Acad Sci U S A 101:11322-11327

Khorasanizadeh S (2004) The nucleosome: from genomic organization to genomic regulation. Cell 116:259-272

Kohzaki H, Murakami Y (2005) Transcription factors and DNA replication origin selection. Bioessays 27:1107-1116

Kouzarides $T$ (2007) Chromatin modifications and their function. Cell 128:693-705

Lagarkova MA, Svetlova E, Giacca M, Falaschi A, Razin SV (1998) DNA loop anchorage region colocalizes with the replication origin located downstream to the human gene encoding lamin B2. J Cell Biochem 69:13-18 
Lemaitre JM, Danis E, Pasero P, Vassetzky Y, Mechali M (2005) Mitotic remodeling of the replicon and chromosome structure. Cell 123:1-15

Linnemann AK, Platts AE, Doggett N, Gluch A, Bode J, Krawetz SA (2007) Genomewide identification of nuclear matrix attachment regions: an analysis of methods. Biochem Soc Trans 35:612-617

Linnemann AK, Platts AE, Krawetz SA (2009) Differential nuclear scaffold/matrix attachment marks expressed genes. Hum Mol Genet 18:645-654

Lipford JR, Bell SP (2001) Nucleosomes positioned by ORC facilitate the initiation of DNA replication. Mol Cell 7: 21-30

Ma H, Samarabandu J, Devdhar RS, Acharya R, Cheng PC, Meng C, Berezney R (1998) Spatial and temporal dynamics of DNA replication sites in mammalian cells. J Cell Biol 143:1415-1425

Maric C, Benard M, Pierron G (2003) Developmentally regulated usage of Physarum DNA replication origins. EMBO Rep 4:474-478

Mechali M (2001) DNA replication origins: from sequence specificity to epigenetics. Nat Rev Genet 2:640-645

Minami H, Takahashi J, Suto A, Saitoh Y, Tsutsumi K (2006) Binding of AlF-C, an Orc1-binding transcriptional regulator, enhances replicator activity of the rat aldolase B origin. Mol Cell Biol 26:8770-8780

Miotto B, Struhl K (2008) HBO1 histone acetylase is a coactivator of the replication licensing factor Cdt1. Genes Dev 22:2633-2638

Mirkovitch J, Mirault ME, Laemmli UK (1984) Organization of the higher-order chromatin loop: specific DNA attachment sites on nuclear scaffold. Cell 39:223-232

Morettini S, Podhraski V, Lusser A (2008) ATP-dependent chromatin remodeling enzymes and their various roles in cell cycle control. Front Biosci 13:5522-5532

Nakamura H, Morita T, Sato C (1986) Structural organizations of replicon domains during DNA synthetic phase in the mammalian nucleus. Experimental Cell Research 165:291-297

Okuno Y, Satoh H, Sekiguchi M, Masukata H (1999) Clustered adenine/thymine stretches are essential for function of a fission yeast replication origin. Mol Cell Biol 19:6699-6709

Papapetrou EP, Ziros PG, Micheva ID, Zoumbos NC, Athanassiadou A (2006) Gene transfer into human hematopoietic progenitor cells with an episomal vector carrying an S/MAR element. Gene Ther 13:40-51

Pappas DL Jr, Frisch R, Weinreich M (2004) The NAD(+)dependent Sir $2 p$ histone deacetylase is a negative regulator of chromosomal DNA replication. Genes Dev 18:769-781

Pasero P, Bensimon A, Schwob E (2002) Single-molecule analysis reveals clustering and epigenetic regulation of replication origins at the yeast rDNA locus. Genes Dev 16:2479-2484

Phi VL, Straetling W (1988) The matrix attachment regions of the chicken lysozyme gene co-map with the boundaries of the chromatin domain. Embo J 7:655-664
Razin SV, Vassetzky YJ, Kvartskhava AI, Grinenko NF, Georgiev GP (1991) Transcriptional enhancer in the vicinity of a replication origin within the $5^{\prime}$ region of the chicken alphaglobin gene domain. J Mol Biol 217:595-598

Rippe K, Schrader A, Riede P, Strohner R, Lehmann E, Langst G (2007) DNA sequence- and conformation-directed positioning of nucleosomes by chromatin-remodeling complexes. Proc Natl Acad Sci U S A 104:15635-15640

Rodriguez-Navarro S (2009) Insights into SAGA function during gene expression. EMBO Rep 10:843-850

Sasaki T, Ramanathan S, Okuno Y, Kumagai C, Shaikh SS, Gilbert DM (2006) The Chinese hamster dihydrofolate reductase replication origin decision point follows activation of transcription and suppresses initiation of replication within transcription units. Mol Cell Biol 26: 1051-1062

Segurado M, de Luis A, Antequera F (2003) Genome-wide distribution of DNA replication origins at A+T-rich islands in Schizosaccharomyces pombe. EMBO Rep 4:1048-1053

Sequeira-Mendes J, Diaz-Uriarte R, Apedaile A, Huntley D, Brockdorff N, Gomez M (2009) Transcription initiation activity sets replication origin efficiency in mammalian cells. PLoS Genet 5:e1000446

Simpson RT (1990) Nucleosome positioning can affect the function of a cis-acting DNA element in vivo. Nature 343:387-389

Stedman W, Deng Z, Lu F, Lieberman PM (2004) ORC, MCM, and histone hyperacetylation at the Kaposi's sarcomaassociated herpesvirus latent replication origin. J Virol 78:12566-12575

Vashee S, Cvetic C, Lu W, Simancek P, Kelly TJ, Walter JC (2003) Sequence-independent DNA binding and replication initiation by the human origin recognition complex. Genes Dev 17:1894-1908

Vincent JA, Kwong TJ, Tsukiyama T (2008) ATP-dependent chromatin remodeling shapes the DNA replication landscape. Nat Struct Mol Biol 15:477-484

Vogelauer M, Rubbi L, Lucas I, Brewer BJ, Grunstein M (2002) Histone acetylation regulates the time of replication origin firing. Mol Cell 10:1223-1233

Vogelstein B, Pardoll DM, Coffey DS (1980) Supercoiled loops and eucaryotic DNA replication. Cell 22:79-85

Wu JR, Gilbert DM (1996) A distinct G1 step required to specify the Chinese hamster DHFR replication origin. Science 271:1270-1272

Wu ZQ, Liu X (2008) Role for Plk1 phosphorylation of Hbo1 in regulation of replication licensing. Proc Natl Acad Sci U S A 105:1919-1924

Yuan GC, Liu YJ, Dion MF, Slack MD, Wu LF, Altschuler SJ, Rando OJ (2005) Genome-scale identification of nucleosome positions in S. cerevisiae. Science 309:626-630

Zhou J, Chau CM, Deng Z, Shiekhattar R, Spindler MP, Schepers A, Lieberman PM (2005) Cell cycle regulation of chromatin at an origin of DNA replication. Embo J 24:1406-1417 